\title{
Are Ethical Issues Becoming Prevalent Among Business Management Researchers?
}

\author{
Freida Ozavize Ayodele ${ }^{1 *}$, Eaw Hooi Cheng ${ }^{1}$, Hasnah Haron², Eyasan Leslie Dabor ${ }^{3}$ \\ ${ }^{1}$ Department of Accounting and Finance, UCSI University, 1 Jalan Menara Gading Taman Connaught, 56000 Kuala Lumpur, Malaysia. \\ ${ }^{2}$ Faculty of Industrial Management, Universiti Malaysia Pahang, 26600 Pahang, Malaysia. \\ 3Department of Accounting, Faculty of Management Science, University of Benin, Benin City, Nigeria.
}

ABSTRACT - This study investigates the prevalence of unethical issues among businessmanagement researchers based on retraction publications from the retraction watch database. Forty-two publications retracted between 2007 and 2019 were analyzed based on the frequency of retraction over time, Journals' impact factors, the type of Journals, the publisher, and the nature of the misconduct. The retraction analysis revealed that research misconduct in business management research is fast evolving around known and emerging themes. The study, therefore, suggests business academics stakeholders rethink the institutional policies for better moral based publication strategies to tackle the upsurge and promotes the continuous supply of reliable information necessary for decision-making in the business management field.
ARTICLE HISTORY

Received: $16-03-2020$

Accepted: 22-06-2020

\section{KEYWORDS}

Business-Management; Retraction; Misconducts; Plagiarism; Key

Performance Index

\section{INTRODUCTION}

The Employment of academic staff at the university often comes with several stringent conditions outlined by the management (Huang, 2015; Ibrahim, Mansor, \& Amin, 2012). These stringent conditions are measured in the form of key performance indexes (KPI) (Varouchas, Sicilia, \& Sánchez-Alonso, 2018). The continuous renewal of the contracts or keeping the faculty position is to a large extent a function of how far the terms and conditions of the KPI are met (Masron, Ahmad, \& Rahim, 2012). One of such components of the KPI is for academics to publish some stipulated number of articles in high impact factor journals indexed in either Scopus or Web of Science (Al-Adawi, Ali, \& AlZakwani, 2016). Therefore, the academic staff is often pressurized to publish their articles in reputable journals amidst other time-demanding responsibilities such as teaching and other administrative responsibilities (Tian, Su, \& Ru, 2016). Since publishing a quality paper is time demanding and requires effort, there are temptations to opt for the easy way to meet up with the KPI within the stipulated time. There is a high tendency for academics to indulge in all sorts of misconduct just to actualize the fastest means of meeting the publication targets (Kampourakis, 2016). Besides meeting the KPI requirement, incentives for publications in high-impact journals could stimulate research misconduct (Heijstra, Steinthorsdóttir, \& Einarsdóttir, 2017; Qiu, 2010). Qiu (2010) pointed out that the pressure to increase the number of publications in high-impact journals could boost misconduct in research publications. Supporting the viewpoint of Qiu (2010), Tian et al. (2016), reported the effect of pressure to publish on young Chinese Scholars. The study revealed that the young Chinese scholars were pressurized to published in internationally indexed journals. Based on the empirical studies, it shows that the young Chinese scholars have tendency to publish papers of less quality or novelty. To support this claim, Sarewitz (2016) also raised a concern on the tendency to water-down quality of paper as a result of pressure to publish.

In business management field, the information generated from published articles is utilized by diverse stakeholders for planning, controlling, resolving problems and making strategic decisions in practice. Unfortunately, there are series of misconduct in diverse fields that have been reported amongst different groups in literature. Research misconduct among doctoral students within clinical research in the University has been investigated by Jensen, Kyvik, Leth-Larsen, \& Erikse (2018). Using a case study of doctoral students in clinical research of the University of Southern Denmark, the finding from the empirical study revealed that some of the students felt pressured to engage in one or more misconducts during doctoral research. Similarly in business management, Hall \& Martin (2019) investigated the rising pressures and the motivations to engaged in misconduct among business school researchers. The study of Hall \& Martin indicates the presence of deliberate misconduct among business school researchers. Although it is good to know that there are willful research misconducts among business management researchers, however, understanding the extent and classes of the misconduct is worthwhile for effective and efficient research publication policies formulations (Awasthi, 2019). Besides, it is possible that the present form of research misconduct in business management is evolving around different themes contrary to that reported in the literature. Tailor-made pragmatic research publication strategies align with the form and the extent of research misconduct will foster the continuous supply of reliable information via published articles necessary for decision-making in the business management field. To gain the needed insight into the prevalence of research 
misbehavior in the business management field, a database like the retraction watch database that specifically deals with misconduct cases in diverse fields becomes vital. Prior research exists on management academic research misconduct based on the analyses of the retracted publications (Ayodele et al., 2019). To the best of the authors' knowledge, analysis on the prevalence of misconduct based on retraction watch database with the motive of fostering the continuous delivery of relevant and reliable information in business via more moral based research strategies is sparse in the literature. Therefore, this study is premised on investigating the nature of misconduct among business management researchers using a retraction watch database. The research is significant as the output could inform the review of existing publication ethical strategies and the development of new ones that align with the evolving nature of research misconducts in the business field. It is expected that the implementation of the ethical strategies will promote integrity in research publications which will, in turn, assist to foster the endless provision of reliable information via published articles in business management field. The period covered in this research is 2007-2019. The study is significant as it extends existing studies to extricate the extent of unethical research practices and how reliable research information provision needed for key decision-making can be promulgated in business management field.

\section{METHODOLOGY}

The data employed in this study was obtained from the retraction watch database (version 1.0.5.5). According to Brainard \& You (2019), the retraction watch database is the largest and most comprehensive database containing over 18000 retracted publications dating back from 1970. Besides, the retraction watch database makes article search and selection easier. Since the focus of the study is to investigate how prevalent is misconduct in business-management research, the search and selection of articles from the database were initiated by choosing the business-management option in the subject list. Other keywords like business, business research, business field were also used for the article search and filtering. The first search resulted in 1680 retracted papers comprises retraction, expression of concern and corrections. Based on the objective of this study which centered on retracted publications, the search and selection of articles was streamlined to only retracted articles on business management. The result shows 96 retracted publications that comprise conference proceedings and journal articles. Subsequently, the search string was limited to only those retracted articles published in journals. The action further reduced the number of retracted articles to 80 . To be sure that only retracted articles within business-management research were included, the selected 80 papers were examined by two independent researchers. After resolving the areas of dispute, the search culminates to just 42 retracted articles on business management. The 42 retracted articles were selected and analyzed based on the year of retractions, impact factors of the journals, the type of publisher, the citation of the original paper before retraction, the country the research was conducted, and the nature of misconducts.

\section{RESULTS AND DISCUSSION}

\section{The trend of retracted publications over time}

Figure 1 depicts the frequency of retracted papers in business-management research from 2007 to 2019 . A total of 42 published articles related to business-management research were retracted between 2007-2019. The frequency of retraction did not follow any regular pattern rather it varies from year to year. This may be due to the time lag between when the article was published and the time the retraction notices were published. An average delay time of 24.37 months was estimated for the retracted papers investigated in this study. Al-Ghareeb et al. (2018) in their study on the retraction of publications in nursing and midwifery research reported an average delay time of 27.6 months (2.3 years) for retracted articles investigated. The lowest number of retracted articles were recorded in 2007 and 2009. While the highest number of retractions were recorded in 2015 .

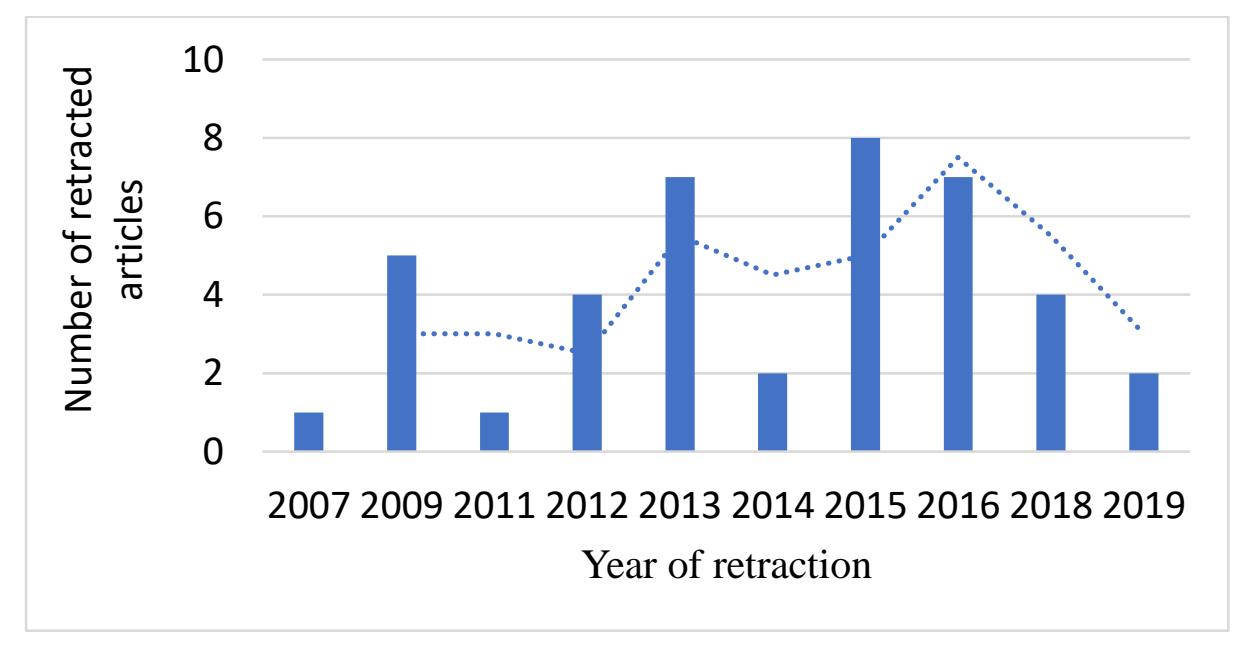

Figure 1: Number of retracted articles in Business-Management research between 2007-2019 


\section{Retracted publications based on the impact factors}

The retracted publications based on the impact factors of the Journals as well as the frequency of the retracted articles are depicted in Figure 2 and Figure 3, respectively. It is obvious that most of the authors published in high impact factor Journals in Business-Management research. The Journal impact factors range from the lowest (0.706) to the highest (7.191). The analysis of the retracted publications shows that the highest number of retracted articles related to BusinessManagement Research was reported in the Journal of Human factor with an impact factor of 1 while at least an article was retracted from each of the high impact Journals shown in Figure 3. This trend revealed that so much importance is attached to publishing in high impact journals probably due to the incentive received by the authors. Gleditsch (2007), reported that institutions often adopt incentive packages to encourage academics to publish in high impact journals. Moreover, funding models are based on the volume and quality of publications. Suo in their study reported that the incentive system has boosted Chinese academic publications in recent years (Suo, 2016). Thereby increases the cases of misconduct as reflected in the number of retracted articles from China. Qiu (2010) reported that the pressure to publish in high-impact Journals could promote misconduct. It is noteworthy that several measures and policies have been put in place by the editorial board of these high-impact Journals to checkmate the cases of misconduct in academic publishing. Based on the analysis in this study, it is apparent that unethical research issues are common in business management including impact factor related journals despite efforts put in place to discourage such practices. Thus, implementation of specific new policies and /or the re-strategizing of current publication policies are needful to curb the pace of misconduct and promote the increase in provisions of reliable information in business management field.

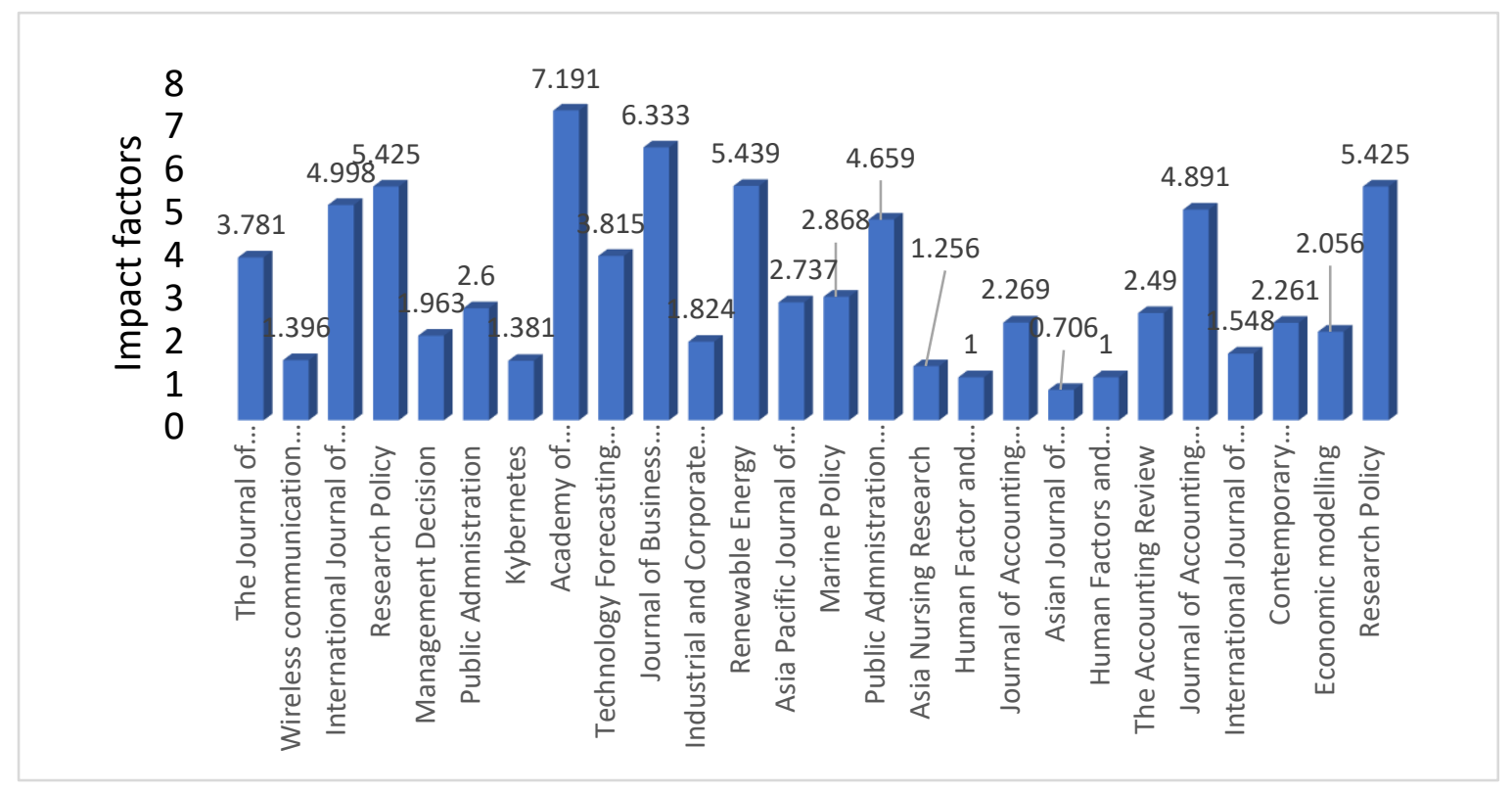

Figure 2: Impact factors of the retracted articles in Business-Management research between

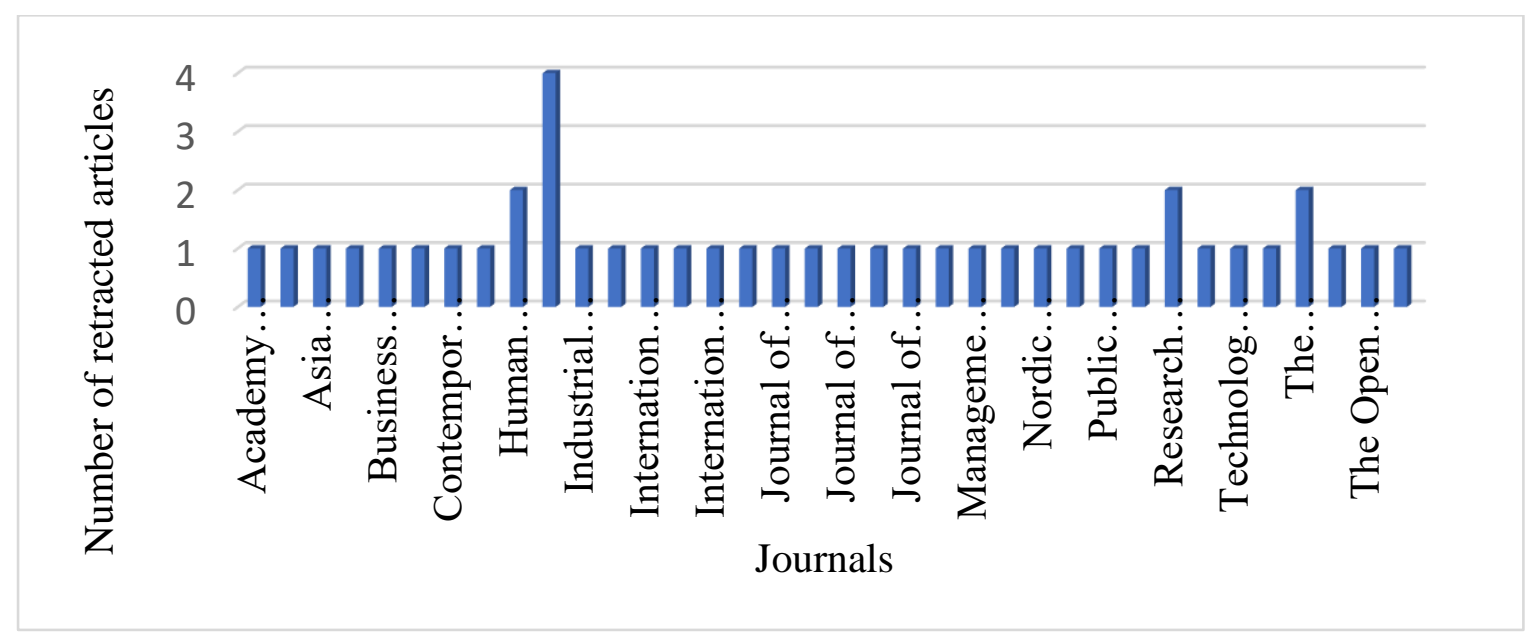

Figure 3: The frequency of retracted publications from the various journal analyzed 


\section{Publisher and Country Analyses of the retracted Journals}

The publisher and the country analyses of the retracted articles are depicted in Figure 4 and Figure 5, respectively. The retracted publications cut across different publishers such as Wiley, Academic of Management, Betham Opens, De Gruyter, Elsevier, Emerald, Hindawi, IEEE, OMICS International, Oxford University Press, Springer, Taylor, and Francis, The America Accounting Association and World Scientific Publishing. This is an indication, that the issues of misconduct in the publication are not taken likely by any of the publishers. However, as seen in Figure 4, the highest number of retractions under study were published by Elsevier-based Journals while the least number of retracted publications were published by World Scientific Publishing Journals. The response to misconduct in publication differs among publishers. Resnik, Wager, \& Kissling (2015) reported the retraction policies among 200 Journals ranked based on the impact factors. The study revealed that most of the Journals had retraction policies in place. Furthermore, the frequency of the retracted articles based on the countries of affiliation of the researcher is depicted in Figure 4. In line with Ayodele, Yao, \& Haron (2019), the trend shows that misconduct in business management publication is a global issue that cut across different countries. Most of the authors of the retracted articles are affiliated to institutions in the US and China. Xie, Zhang, \& Lai (2014) reported that China as a major contributor to Science and Technological research is also experiencing challenges in high rises of research misconducts.

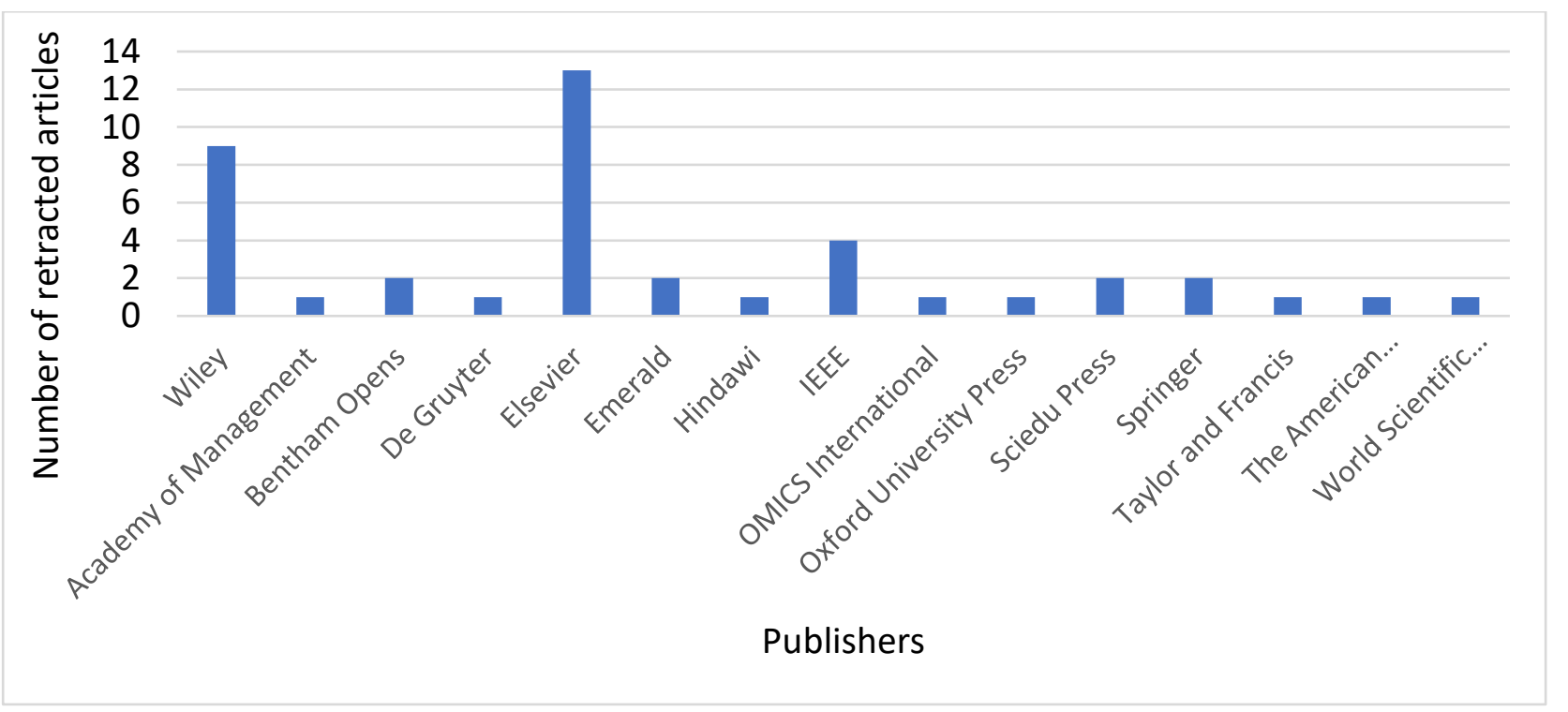

Figure 4: The frequency of the retracted publications based on the various publisher analyzed

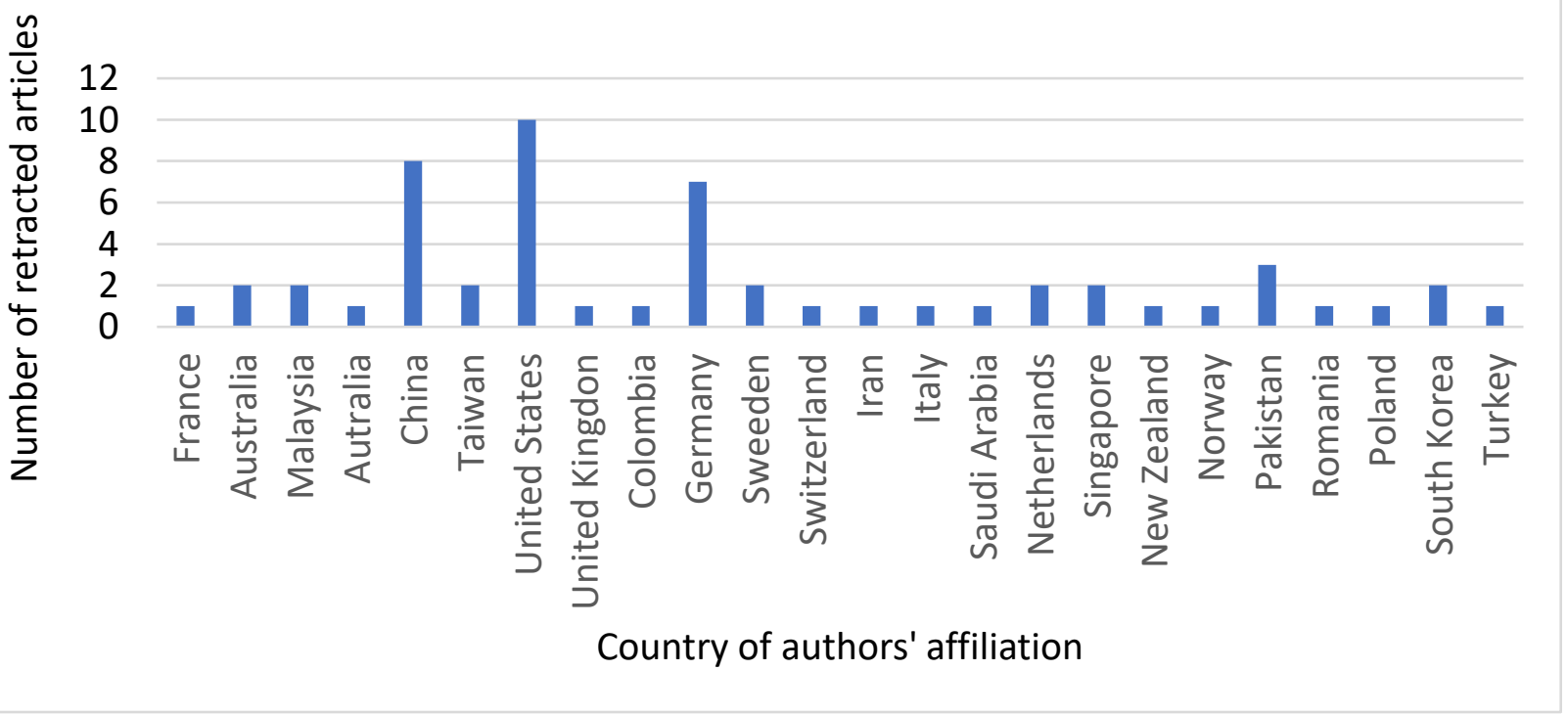

Figure 5: Frequency of the retracted articles based on the country of the authors' affiliation 


\section{Analysis of Research Misconduct}

The detail analyses of the different types of misconducts reported in the retracted publications based on the retraction watch database are represented in Figure 6. Publication misbehaviour in Business-Management research is in different forms. The most pronounced of the misconduct analyzed from the retracted publication include plagiarism, fake peer review, fabrication and falsification of data, duplication of articles, errors in methods and duplication of data which accounted for $15 \%, 7 \%, 7 \%, 9 \%, 7 \%$, and $7 \%$, respectively. Other minor cases reported include conflict of interest, lack of approval from the third party, non-disclosure of closely related paper, copyright claim, forged authorship. $13 \%$ of the retracted publications analyzed did not show the details of the misconduct. While about $7 \%$ of the retracted articles were attributed to the errors from the Journals.

In the work of Stretton et al. (2012) which involves the analysis of 213 retracted misconduct publications, $41.8 \%$ of the retracted articles were attributed to plagiarism, 52.1\% was attributed to falsification/fabrication of data, while ethical issues and authors' dispute accounted for $2.3 \%$ each. Of the 213 retracted publications, $1.4 \%$ did not have details of the nature of the misconduct. Although, plagiarism and falsification/fabrication are the rampant form of misconduct in business management research, nevertheless, new forms of misconduct are evolving as observed in this study (Laskar, 2017). Lacetera \& Zirulia (2011) reported that the perpetuation of diverse form of research misconduct often come with huge costs implication. As the study illustrates the manner of soaring research misconducts in business field, more attention should be paid to tackling the emerging nature of research misconducts in business management research to avoid the incidental costs that are not beneficial, and review instituted ethical research codes for improvement where necessary.

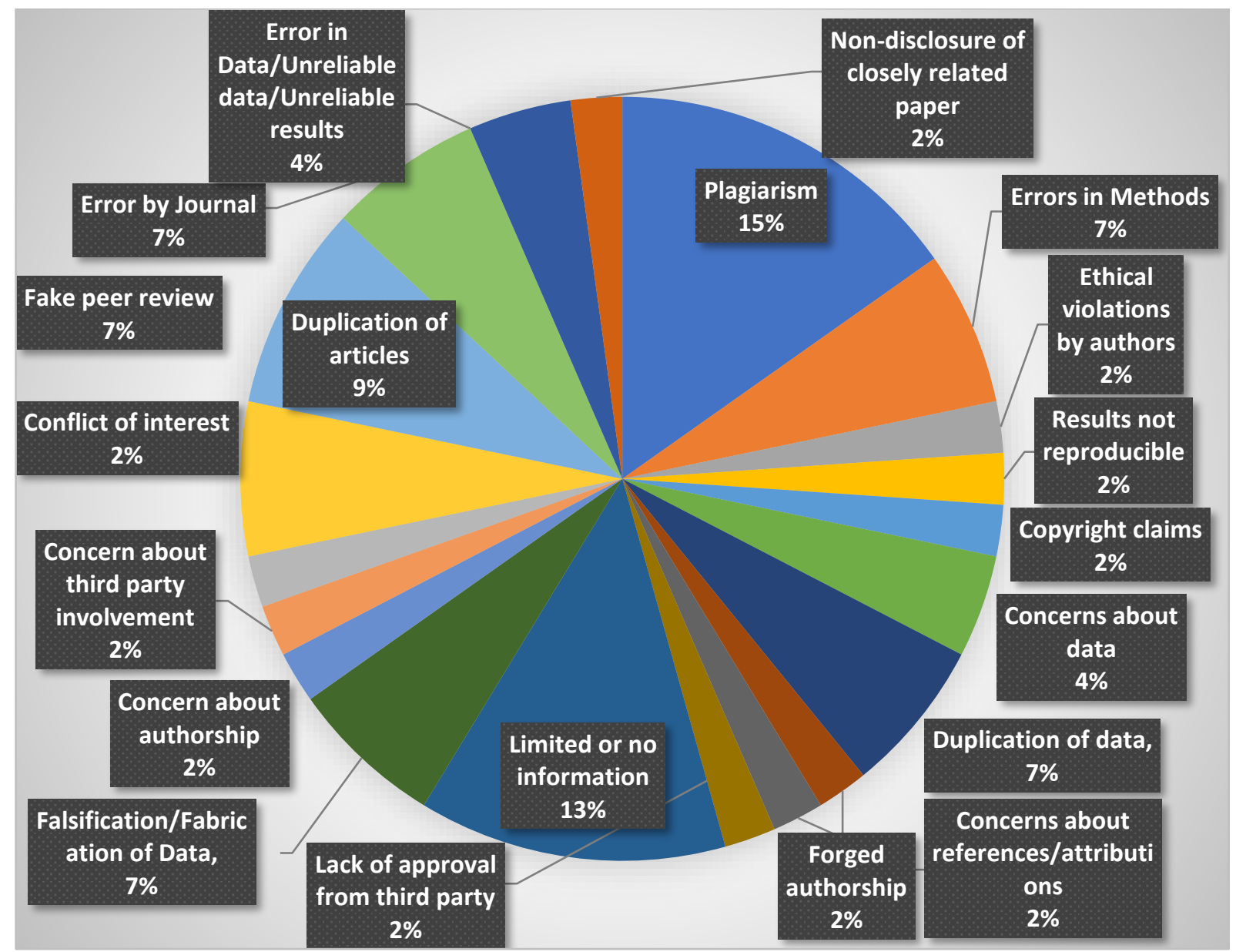

Figure 6: The different categories of misconduct observed in Business-Management research

\section{CONCLUSION AND PRACTICAL IMPLICATIONS OF THE STUDY}

The study examined the prevailing cases of misconduct in business-management research based on the analysis of retracted publications from 2007 to 2019 . The analyses of the retracted publications revealed that misconduct in businessmanagement research is an issue that has been evolving over the years and unresolved. The continuous rise in plagiarism, falsification, and fabrication signifies the need for an overhaul of the existing ethical research policies and publication processes. Business management research policies that motivate academics and researchers to publish in impact factor journals without indulging in research misconduct should be upheld. Perhaps, there should be an incentive system in place 
for authors whose articles are not retracted to curb the upsurge in unethical research practices in business management research. The incentive mechanism could be monetary and non-monetary related set-up by the author affiliated institutions following the given KPI.

Aside from the well-known forms of misconduct such as plagiarism and fabrication/falsification in literature, the study finds out that new forms of misconduct are emerging. Drawing from the updated Committee on Publication Ethics (COPE) guidelines on retraction, categorized as emerging research misconduct issues in this research are unreliable findings resulting from miscalculation/experimental errors, publications of previous findings without proper attribution to previous sources; contains material or data without authorization for use; infringement on copyright; manipulated peer review; and failure to disclose competing interest (COPE, 2019). The study, therefore, recommends an increase in the sensitization of authors and intending authors by diverse stakeholders on the necessity to abide by research publication ethics. In agreement with authors like Awasthi (2019), institutions should organize seminars/workshops and take other proactive measures that emphasize integrity-based research to enhance information quality in the business management field. In addition, future studies could investigate what should make up the composition of such training endeared to foster transparency and integrity in research.

Faria (2018) suggested social control mechanisms as a way of addressing research misconduct. A social control mechanism is a scenario whereby a special body is mandated to investigate and sanction anyone found guilty of misconduct. Despite instituting the social control mechanism by respective publication stakeholders to encourage the design of research inbuilt with ethical principles, business management unethical research matter is still prevalent. This study, therefore, proposes a complementary perspective to the existing social control mechanisms defined by Faria (2018). The social control medium prescribes in the research is the use of social networks to motivates morally compliant research publications devoid of research misconduct. That way, more people can be directly and indirectly influenced by their counterparts/friends on the same network of collaborations. Al-Adawi, Ali, \& Al-Zakwani (2016) indicated the existence of publishing or perish policies in institutions that are linked with research misconduct. Based on the insight from Frith (2019) and Ayodele, Yao, \& Haron (2019), the university management should reconsider the policy of "publish or perish" and proffer more innovative ways that focus on addressing both personal and non-personal related factors that are linked with unethical research practices. That way, more impactful research publication ethical policies that enhance the continuous delivery of relevant and reliable information in business can be formulated and implemented. Hence, future studies should further empirically examine how and why effective and efficient mixed research publication strategies that discourage research misconduct and contributes to useful information requirement rather than the quantity are needed in the business management field.

The study is limited in that only the output of research misconduct in the business field from the retraction database is utilized. As such, there is a possibility that retracted articles in business-related fields that exist in other databases may have been omitted from the analysis. The study, therefore, recommends that future research should employ more than one database in the future when examining integrity in business research.

\section{REFERENCES}

Al-Adawi, S., Ali, B. H., \& Al-Zakwani, I. (2016). Research misconduct: The peril of publish or perish. Oman Medical Journal, 31(1), 5-11. https://doi.org/10.5001/omj.2016.02

Al-Ghareeb, A., Hillel, S., McKenna, L., Cleary, M., Visentin, D., Jones, M., ... Gray, R. (2018). Retraction of publications in nursing and midwifery research: A systematic review. International Journal of Nursing Studies, 81(January), 8-13. https://doi.org/10.1016/j.ijnurstu.2018.01.013

Ayodele, F. O., Yao, L., \& Haron, H. (2019). Promoting Ethics and Integrity in Management Academic Research: Retraction Initiative. Science and Engineering Ethics, 25(2), 357-382. https://doi.org/10.1007/s11948-017-9941-z

Awasthi, S. (2019). Plagiarism and Academic Misconduct: A Systematic Review. DESIDOC Journal of Library \& Information Technology, 39(2).

Bosch, X., Hernández, C., Pericas, J. M., Doti, P., \& Marušić, A. (2012). Misconduct Policies in High-Impact Biomedical Journals. PLoS ONE, 7(12), 1-9. https://doi.org/10.1371/journal.pone.0051928

Brainard, J., \& You, J. (2019). What a Massive Database of Retracted Papers Reveals About Science Publishing's "Death Penalty." Sciences, 25(1), 1-5. https://doi.org/10.1017/CBO9781107415324.004

COPE. (2019). Our core practices. Retrieved from https://publicationethics.org/

Faria, R. (2018). Research Misconduct as White-Collar Crime: A Criminological Approach (Palgrave M). Porto, Portugal: Faria, Rita. Retrieved

from https://books.google.com.my/books?hl=en\&lr=\&id=H3hvDwAAQBAJ\&oi=fnd\&pg=PR9\&dq=social+control+mechanism+in +research+misconduct..Faria\&ots=UugdWUEfHX\&sig=Eb8j6h_eDYEsKMzwGA_wXAUg328\&redir_esc=y\#v=onepage\&q =social control mechanism in research misconduct..Far

Frith, U. (2019). Fast lane to slow science. Trends in Cognitive Sciences, xx(xx), 1-2. https://doi.org/10.1016/j.tics.2019.10.007

Gleditsch, N. P. (2007). Incentives To Publish. European Political Science, 6(2), 185-191. https://doi.org/10.1057/palgrave.eps.2210128

Hall, J., \& Martin, B. R. (2019). Towards a taxonomy of research misconduct: The case of business school research. Research Policy, 48(2), 414-427. https://doi.org/10.1016/j.respol.2018.03.006

Heijstra, T. M., Steinthorsdóttir, F. S., \& Einarsdóttir, T. (2017). Academic career making and the double-edged role of academic housework. Gender and Education, 29(6), 764-780. https://doi.org/10.1080/09540253.2016.1171825 
Huang, F. (2015). The Changing Academic Profession in Asia: The Challenges and the Transformation of Academic Profession in Asia; Report of the International Conference on the Changing Academic Profession Project, 2015. https://doi.org/10.1080/0034408730680212

Ibrahim, R., Mansor, A. Z., \& Amin, L. (2012). The Meaning and Practices of Academic Professionalism: Views from Academics in a Research University. Procedia - Social and Behavioral Sciences, 59, 520-527. https://doi.org/10.1016/j.sbspro.2012.09.309

Jensen, L. B., Kyvik, K. O., Leth-Larsen, R., \& Erikse, M. B. (2018). Research integrity among PhD students within clinical research at the University of Southern Denmark. Ugeskrift for Laeger, 180(8), 694-694.

Kampourakis, K. (2016). Publish or Perish? Science and Education, 25(3-4), 249-250. https://doi.org/10.1007/s11191-016-9828-4

Lacetera, N., \& Zirulia, L. (2011). The economics of scientific misconduct. Journal of Law, Economics, and Organization, 27(3), 568603. https://doi.org/10.1093/jleo/ewp031Laskar, M. S. (2017). Publishing articles in scientific journals: a concern for research misconduct or dishonesty (fabrication, falsification and plagiarism). Mediscope, 4(2), 1-4.

Masron, T. A., Ahmad, Z., \& Rahim, N. B. (2012). Key Performance Indicators vs Key Intangible Performance Among Academic Staff: A Case Study of a Public University in Malaysia. Procedia - Social and Behavioral Sciences, 56(Ictlhe), 494-503. https://doi.org/10.1016/j.sbspro.2012.09.681

Qiu, J. (2010). Publish or perish in China: the pressure to rack up publications in high-impact journals could encourage misconduct, some say Citation. Nature, 463(7278), 142-143.

Resnik, D. B., Wager, E., \& Kissling, G. E. (2015). Retraction policies of top scientific journals ranked by impact factor. Journal of the Medical Library Association, 103(3), 136-139. https://doi.org/10.3163/1536-5050.103.3.006

Sarewitz, D. (2016). The pressure to publish pushes down quality. Nature, 533, 147. https://doi.org/10.1038/533147a

Stretton, S., Bramich, N. J., Keys, J. R., Monk, J. A., Ely, J. A., Haley, C., ... Woolley, K. L. (2012). Publication misconduct and plagiarism retractions: A systematic, retrospective study. Current Medical Research and Opinion, 28(10), 1575-1583. https://doi.org/10.1185/03007995.2012.728131

Suo, Q. (2016). Chinese Academic Assessment and Incentive System. Science and Engineering Ethics, 22(1), 297-299. https://doi.org/10.1007/s11948-015-9643-3

Tian, M., Su, Y., \& Ru, X. (2016). Perish or Publish in China: Pressures on Young Chinese Scholars to Publish in Internationally Indexed Journals. Publications, 4(2), 9. https://doi.org/10.3390/publications4020009

Varouchas, E., Sicilia, M. ángel, \& Sánchez-Alonso, S. (2018). Academics' perceptions on quality in higher education shaping key performance indicators. Sustainability, 10(12), 1-16. https://doi.org/10.3390/su10124752

Xie, Y., Zhang, C., \& Lai, Q. (2014). China's rise as a major contributor to science and technology. Proceedings of the National Academy of Sciences of the United States of America, 111(26), 9437-9442. https://doi.org/10.1073/pnas.1407709111

\section{AUTHORS' BIOGRAPHY}

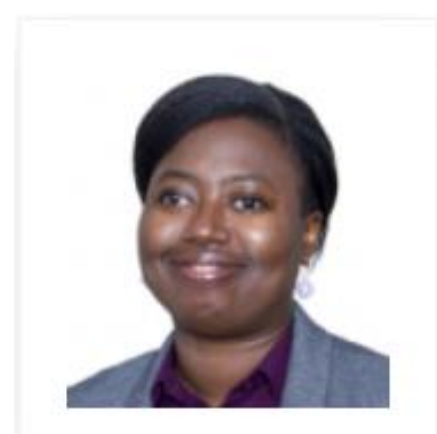

\section{Dr. Freida Ozavize Ayodele}

Dr F.O.Ayodele research expertise focus on managerial ethics, financial accounting, and quality management. She is presently a Leactuer at the Department of Accounting and Finance, UCSI University, Kuala Lumpur, Malaysia with years of research and teaching.

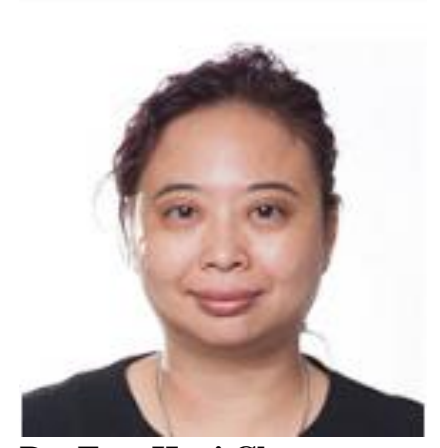

Dr. Eaw Hooi Cheng 
Dr. Eaw Hooi Cheng is an Assistant Professor and the Head of Programme of Accounting and Finance, Faculty of Business and Information Science, UCSI University, Kuala Lumpur, Malaysia. Her research focus on Social Sciences in relation to behavioral psychology such as financial behavioral and other relation areas of cost management and accounting related issues.

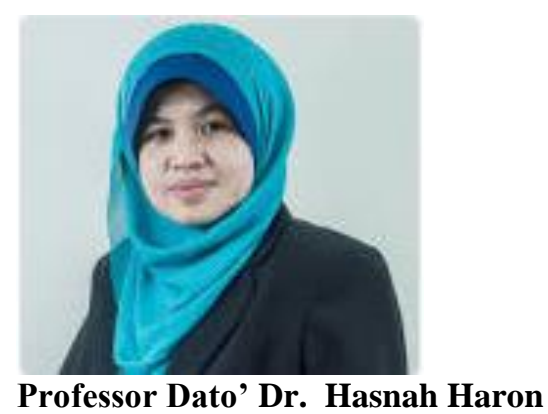

Hasnah Haron has been a Professor of Auditing at the Faculty of Industrial Management, Universiti Malaysia Pahang. She has more than 25 years of experience in research and teaching. She has published several articles in international refereed journals as well as Professional Accounting journals.

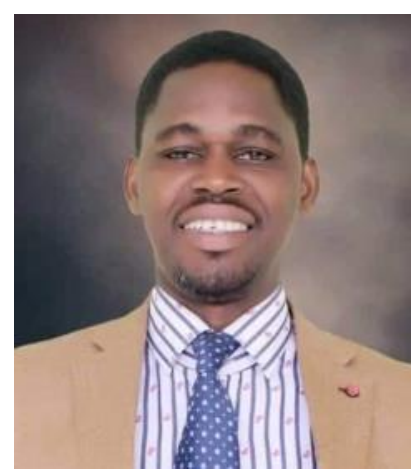

\section{Professor Eyasan Leslie Dabor}

E.L Dabor is a Professor of Accounting at the Department of Accounting, University of Benin, Benin City Nigeria. He has several years of research and teaching experience. His research area include managerial accounting, corporate governance and other related accounting issues. He has published several articles in international and national refereed journals. 